\title{
People recognition: a historical/anthropological perspective
}

\author{
A. Ardila \\ Instituto Colombiano de Neuropsicología, Bogotá, Colombia \\ Correspondence to: A. Ardila, Apartado Aéreo 17021, Bogotá, Colombia, South America
}

\begin{abstract}
Using current neurological and neuropsychological literature, and the analysis of different cultural and historical conditions, people recognition is analyzed. Different "subsystems" or "modules" could be involved in individuals' recognition: living versus non-living, own species versus other species, familiar versus non-familiar, males versus females, and individual identification versus emotional identification. Not only visual, but also auditory and even olfactory information may be involved in people recognition. Visual information involved in people recognition is proposed to include not only the perception of faces, but also the perception of whole body and gait, clothes, emotional expressions, and individual marks.
\end{abstract}

Keywords: Emotional expression - People recognition - Phanagnosia - Prosopagnosia - Prosopamnesia - Sign stimulus

\section{INTRODUCTION}

Recognition of own-species members represents a basic survival ability not only for prehistoric and contemporary humans, but also for every living creature. Lacking this ability, any species would quickly disappear. Recognition of own-species members may be based on a wide range of multiple sensory information. For instance, insects rely especially on olfactory information to identify other members of their own species, whereas primates rely mainly, but not exclusively, on visual information (Jolly, 1972; Hinde, 1974).

In humans, the critical and distinguishing signal features used in the recognition of other species members have somehow evolved in a parallel way with cultural evolution, as a result of the use of different clothes, costumes, paintings, hairstyles, make-up, etc.

Paleolithic humans most likely lived in small social groups, similar in size to a primate troop, that is, about 10-100 individuals, composed of one or several couples and their offspring. In fact, in modern society we are still effectively living in a small primate-like band composed of some 10-100 individuals-relatives and friends-with whom we maintain a close relationship. However, the number of faces that we are potentially able to recognize"familiar faces"- can be of the order of several thousands. Some primitive societies that depend on hunting and gathering of patchily distributed resources form casual societies not unlike the primate model (Lee and DeVore, 1968; Wilson, 1975), and the primate model was most likely the first type of social organization (Van den Berghe, 1979).
For the prehistoric human, recognition of other species members was most critical. According to the living conditions of the prehistoric human, people recognition consisted of answering at least the following questions: (1) Does the other individual belong to the same species or not (i.e. is he/she another Homo sapiens individual)? (2) What is his or her gender? (3) What is his or her emotional state; i.e. is he or she a friend or an enemy? Is he or she a known (endogroup member, "familiar individual") or unknown (exogroup person, "non-familiar individual") person? (4) What particular individual is he or she?

\section{OWN-SPECIES MEMBERS' RECOGNITION}

Recognition of own-species members does not seem so critical for the contemporary human as it was for prehistoric humans. However, for people currently living in the Amazonian jungle it may still be equally critical. It is evident that in Bogotá or London the chance of meeting a member of another species is quite low. For the prehistoric human (and for contemporary Tucano Indians living in the Amazonian jungle) however, a moving animal might raise the question of species identification.

Brain organization for other-people recognition has been studied under normal, but mostly under pathological conditions. Its disturbance is usually known as prosopagnosia (e.g. Bodamer, 1947; Damasio et al., 1982). Specialized brain areas involved in face recognition have been studied. Usually, the occipito-temporal area, either bilaterally (e.g. Meadows, 1974; Damasio et al., 1982; 
Bruyer et al., 1983; Ettlin et al., 1992) or unilaterally (e.g. Whitely and Warrington, 1977; De Renzi, 1986a; Landis et al., Benton, 1990), has been associated with disturbances in face recognition.

Although testing for prosopagnosia is usually carried out using photographs of faces, this obviously represents an extremely artificial situation. It is interesting to note that untrained people are unable to recognize individual faces and even everyday objects in photographs. Modiano et al. (1982) observed in Mexican Indian children an average error rate of $20 \%$ in identifying color paintings of everyday objects. Recognition of individuals in photographs represents a learned and highly trained ability that we usually take for granted. Young children have great difficulty in recognizing even their own parents and siblings in photographs. This ability is usually achieved around the age of 2 years, if adequate training opportunities are provided.

People recognition disturbances usually present some specific characteristics: (1) prosopagnosic patients usually recognize different human races (Caucasian, Mongoloid, Black), and they can sort human and animal faces (Benton, 1980, 1990; De Renzi, 1986b); (2) they can also distinguish fruits from flowers, and cars from furniture, although they do not know what specific category member it is (i.e. what particular fruit, flower, car, or piece of furniture); (3) prosopagnosic patients usually recognize the general category "human face" (or "fruit" or "flower"), and can separate human faces from their corresponding cartoons (Lopera and Ardila, 1992), but they fail in recognizing the individual members of the category. These clinical characteristics suggest the existence of a highly specialized brain system adapted to recognize own-species members.

Nonetheless, although prosopagnosic patients can usually separate pictures of people (own species) from pictures of animals (other species), they can fail in performing this task (Bornstein et al., 1969; Benson et al., 1974). This suggests an impairment in those specialized own-species brain detector systems.

Farah et al. (1991) have pointed out that the visual recognition of living and non-living things can be selectively impaired in cases of brain damage. Patients with prosopagnosia can present difficulty in recognizing animals and plants; nonetheless, they usually present a better preserved ability to recognize inanimate objects. A neural system more important for distinguishing living from non-living things was proposed by the authors; this system can be selectively impaired by brain damage. Higher visual centers would be specialized not just to recognize faces, but for the perception of biological forms. One subsystem of this higher system specialized in the perception of biological forms would correspond to "human face recognition".

Farah et al.'s (1991) point of view in general supports the perceptual model proposed by Konorski (1967). This perceptual model postulates the existence of different gnosic brain areas specialized in the recognition of manipulable and non-manipulable objects, human faces, emotional facial expressions, and animated objects. By the same token, in cases of anomia associated with brain damage, it has been observed that some specific semantic categories can be selectively impaired, while others are better preserved (Warrington and Shallice, 1984). This specificity has been shown also in memory (Farah et al., 1989). This implies the existence of highly specialized brain perceptual and memory systems.

Human species members recognize one another basically (although not exclusively) through visual information. Ethology has carefully studied different species' "sign stimuli" (Tinbergen, 1951; Eibl-Eibesfeldt, 1970). A sign stimulus refers to some feature of the object that has been shown to be of major importance in eliciting response (Hinde, 1970). The human face could evidently be considered as a "sign stimulus".

The visual recognition of own-species members, as well as the auditory recognition of own-species calls, in several animal species (including humans), have been shown to be somehow biologically programmed. Some neurons in the auditory cortex of different animals only fire when using same species calls (Brugge and Reale, 1985), and this probably also holds true when visually perceiving members of the same species (Gross et al., 1972; Rolls, 1984). Perret et al. (1982) found that about $10 \%$ of the neurons they sampled in the superior temporal sulcus of the macaque monkey selectively responded to faces and not to other stimuli. Desimone et al. (1984) found in this same area that $34 \%$ of the sampled neurons selectively responded only to faces. Baylis et al. (1985) observed that $77 \%$ of 44 face neurons in this temporal area reliably responded more to some specific faces than to others. Perret et al. (1984) claim to have found cells that are only responsive to a particular human face often seen by the monkey. Further, Heywood and Cowey (1992) described cortical neurons that are selectively sensitive to faces, parts of faces and particular facial expressions concentrated in the banks and floor of the superior temporal sulcus in macaque monkeys. The neurons of the superior temporal sulcus of monkeys would be, in consequence, part of a system specialized in faces. Ojemann et al. (1992) recorded neuronal activity in adult human subjects, and observed that $62 \%$ of the studied neuronal populations in the non-dominant temporal lobe presented significant changes in activity during matching of faces, and $52 \%$ during labeling of facial emotional expressions. These results would support the specificity of a highly specialized neuronal face recognition brain system.

Although the overwhelming majority of cases of prosopagnosia reported in the literature presented, in 
addition to the face recognition impairments, some associated deficits in the recognition of individual members belonging to other visual categories (most often, living things - fruits, flowers, etc. - but also non-living thingsbuildings, cars, furniture, etc.), prosopagnosia can be restricted occasionally to the recognition of faces (De Renzi, 1986a; Farah, 1990; De Renzi et al., 1991). Conversely, there are patients with severe visual agnosia for real objects without any evident defect in face recognition (Hécaen and Ajuriaguerra, 1956; Feiberg et al., 1986). Further, prosopagnosic patients can be capable of performing very complex perceptual tasks and can perceive and recognize many stimuli that are visually more complex than human faces (Benton and Van Allen, 1972; Damasio, 1985). This suggests a specificity in face recognition defects.

In conclusion, it seems reasonable to assume the existence of some brain neuronal subsystems specialized in the recognition of own-species members. These subsystems would participate in a higher neuronal system specialized in the recognition of biological forms. Individual members (individual faces) would be encoded into the "face recognition subsystem". The record of neuronal activity supports the existence of highly specialized neuronal subsystems involved in the perception of faces (Gross et al., 1972; Perret et al., 1982; Rolls, 1984; Desimone et al., 1984; Heywood and Cowey, 1992; Ojemann et al., 1992).

\section{GENDER RECOGNITION}

Gender recognition (filongnosis, from the Greek filon $=$ gender) represents a crucial perception that will define all further behavior (both 100000 years ago and today). Taking into account that in humans a moderate sexual dimorphism exists (females usually are of a smaller height, and possess sexual signals that can be easily recognized either from the front or the back; additionally, gait is different), it is easy to suppose that visual signals were as relevant and effective for the prehistoric human, as they continue to be for the contemporary human (Morris, 1977). Further, not only body configuration but also the clothes of males and females are quite different and identifiable in their construction, shape, and even colors. Some female primates have areas of "sexual skin" which swell and/or change color with changes in the reproductive state of the animal (Hinde, 1974).

Prosopagnosic patients are sometimes unable to distinguish male and female faces (e.g. Bruyer, 1986; Damasio et al., 1990; Lopera and Ardila, 1992), and it might be proposed that they will also present general defects in recognizing males and females according to other (not facial) sexual signals. They might also present a kind of whole-body recognition defect. The prosopagnosic patient described by Bauer (1982) decided to cancel his subscription to the journal Playboy after becoming prosopagnosic; Bauer suggested that his patient presented an agnosia for individual nudes, analogous to a defect in the recognition of individual faces. The author of this paper recently studied a prosopagnosic patient with a virtually complete inability to recognize any face, and even to sort male and female faces. However, he easily and accurately distinguished male and female nudes. This implies that facial and whole-body male-female distinction can become dissociated, or at least, that body recognition can be preserved, while face recognition is impaired. If this last assumption were true, it would imply a "sensitivity hierarchy": it is easier (and better preserved in brain-damaged patients) to recognize males-females using wholebody than facial signals.

Nonetheless, visual signals are not the only ones in gender recognition: there are also auditory signals resulting from a different voice timbre, and also distinctive olfactory signals. Auditory and olfactory signals are probably more readily used in low illumination conditions, while visual signals are easily available in daytime conditions.

These visual, auditory and olfactory gender signals still exist in contemporary humans, despite the differences in cultural backgrounds. Visual marks have not changed, although they can be covered. Height differences remain, although women may use higher shoes for increasing their height. The differences in gait are evident. Voice timbre differences supposedly have not changed during the last 50000 years. Olfactory signals can be artifically covered and replaced by other new olfactory signals, but they are still gender marks.

Olfactory recognition deserves some consideration. Olfactory signals play a crucial communication role in most animals, including primates (Hinde, 1970; Jolly, 1972). Very often, sexual behavior is partially under olfactory control: a pheromone is produced that acts as a powerful attractant to the male. The tendency of women living together to menstruate simultaneously may be mediated by olfactory stimuli (Carlson, 1986). A male pheromone is detected most easily by women of reproductive age, but men can smell it if given oestrogen; and olfactory thresholds have been observed to vary during the menstrual cycle (Comfort, 1971; Eibl-Eibesfeldt, 1970; Hinde, 1974). So, olfactory signals continue being effective in gender identification. The perfume industry has become a solid and well-established enterprise.

In summary, gender identification can be mediated by different types of signals: facial, whole body, and even auditory and olfactory signals.

\section{EMOTIONAL EXPRESSION AND RECOGNITION}

Some basic emotional expressions are universal, and can be easily recognized by any member of any culture. 
Aggressive gestures, protective gestures, threatening signals, submissive postures, and sexual approach signals are roughly identical in any cultural group, and are quite similar to those observed in non-human primates (Eibl-Eibesfeldt, 1970; Morris, 1977). It can be supposed that they existed in a similar form in the prehistoric human. Some other emotional expressions present (major or minor) variations across different cultural groups. Surprise, joy, mourning, etc., can present important cross-cultural differences. Special ornaments are often used to make a certain emotional state even more easily identifiable: aggression, sexual interest, mourning, etc. (Eibl-Eibesfeldt, 1973).

During child development, the face represents the earliest visual stimulus capable of producing an emotional response (Fantz, 1961). Facial identification and emotional recognition can be dissociated in brain-damaged individuals. In some cases of prosopagnosia the recognition of facial expression is preserved while face identification is impaired (e.g. Shuttleworth et al., 1982; Bruyer et al., 1983). Conversely, some brain-damaged patients still have the ability to identify faces, but fail in recognizing facial emotional expressions. Most often right hemisphere-damaged patients present serious difficulties in identifying, matching and comprehending emotional expressions (Feyereisen, 1986). Kurucz and Feldmar (1979) found that certain patients could recognize photographs of famous faces, but they were unable to identify their facial expressions. By the same token, the patient reported by Lopera and Ardila (1992) did not recognize facial emotional expressions, but usually was able to deduce them (e.g. "This must be a smiling and happy face, because the teeth are seen through the mouth").

It becomes plausible that facial identification and the recognition of emotional expressions depends, at least partially, on different brain subsystems. Two different visual agnosic syndromes could be found in brain-damaged patients: agnosia for faces (prosopagnosia) and agnosia for emotional expressions (prosopo-affective agnosia). Konorski (1967) proposed the existence of different brain systems (different "gnostic areas") for recognizing human faces and emotional facial expressions. Etcoff (1984) postulated the existence of different "modules" for the visual identification of faces and facial expressions. She observed that the speed and accuracy with which normal subjects performed a sorting task (putting photographs of faces in different piles according to either their identity or their expression) was not affected by whether facial identity was correlated with facial expression, implying that these two properties of faces are processed independently. Etcoff postulated that two separate brain modules underlie the recognition of facial identity and facial expression, but that they are neuroanatomical neighbours.

Recently, it has been shown that prosopagnosic patients can retain some covert face recognition. These patients present a physiological response for familiar, but not for unfamiliar faces (Bauer, 1984; Tranel and Damasio, 1985; De Haan et al., 1987; Young and De Haan, 1988; De Haan et al., 1992). By the same token, in associative learning tasks, performance is better if familiar faces are used (Bruyer et al., 1983). These findings suggest that despite unawareness in face recognition, some covert face recognition can remain in the prosopagnosia syndrome. However, this is not really surprising: everyday experience shows that very often, when seeing a particular face, we can be totally unable to identify who he or she is, despite having the "feeling" that we know that particular individual; we simply have a "feeling of familiarity". The recognition of the individual member may be impossible in this everyday experience (and can be impaired in cases of brain damage), but the distinction "familiar" and "not familiar" remains.

\section{INDIVIDUALS' RECOGNITION}

Own-endogroup members are usually very alike (resulting from endogamy) in their height, body shape, skin color, and additionally, in the clothes and make-up they wear. Usually they can be visually identified even at long distances.

Erroneously we have learned that individuals are recognized just by their faces. This can be partly true in our urban societies, where we have very limited opportunity for perceiving other individual characteristics (e.g. his or her body configuration, gait, etc.; watching people's body configuration and gait has become impolite in our societies; ethologists, however, assure us that we would like to do it: Eibl-Eibesfeldt, 1970; Hinde, 1974; Morris, 1977). In a survey of 1000 photographs of people (excluding advertisements) randomly taken from the two most influential newspapers and the two most influential magazines in Colombia, it was found that face photographs were about four times more frequently published than wholebody photographs. Evidently, we are overtrained in individuals' recognition relying only on facial cues. However, facial information is quite insufficient for recognizing individuals for anybody living in the country, in open fields or in savannas. People living in the eastern plains of Colombia easily recognize approaching or passing people when they are still $500 \mathrm{~m}$ or further away. They do not depend, of course, solely upon face recognition for identifying individuals (faces can be recognized only within very short distances), but upon a broader range of signals: body configuration, gait, and even clothes. The human brain should possess not simply a system for encoding and memorizing faces (prosopagnosis) but also for encoding and memorizing body configurations and general personal features ("prosopos" in Greek means not only face, but 
also person, and prosopagnosia should be understood as the inability to identify not simply faces, but people).

Recognition of individuals and recognition of faces is not equivalent. The face is only one of the visual characteristics used to recognize individuals, and it was not the most important one for the prehistoric human (or for current jungle inhabitants, or for army members), although evidently it is the most important one in our current city environment. Theoretically, we could suppose that in addition (or superimposed) to the ability to recognize faces, the human brain should possess an ability to recognize individual body configurations and body marks. Furthermore, faces yield information not only about the individual, but also (and perhaps more importantly) about his or her specific emotional state.

Identifying individual members involves recognizing body marks and general configuration (somagnosis, that is, body recognition), and face signals (prosopagnosis, according to the current use). Patients with prosopagnosia cannot discriminate individual members in a group, but they can perceive evident visual marks (e.g. a face with wrinkles means that it should correspond to an elderly person; a face with a beard should correspond to a male, etc.).

Somagnosis has not yet been systematically analyzed in neuropsychology. Further, it does not appear easy, considering that currently the most important body marks are the clothes (changing from one day to another), although it seems that some people possess a tremendous ability to identify individuals by their clothes. Our knowledge about other people's body configurations is in most cases only approximate. However, it is evident that in addition to memory for people's faces, we also have some memory for people's height, shape, gait, etc. It is reasonable to suggest that patients presenting face recognition deficits may present also body recognition defects (see above). It is interesting to note that patients with prosopagnosia usually present difficulties recognizing animals, either animal faces or whole-body recognition (Farah et al., 1989). Damasio et al. (1982) reported a prosopagnosic patient who had difficulty in identifying people's gaits.

Different anatomical substrates have been suggested for the distinction of familiar and non-familiar faces (Warrington and James, 1967). Non-aphasic patients with right posterior lesions present the most remarkable difficulty in discriminating familiar faces. Lopera and Ardila (1992) proposed two different neuropsychological syndromes: prosopagnosia (as a more or less isolated perceptual defect in face recognition), and prosopamnesia (as a memory defect for faces). In the first case right occipital-temporal damage would be sufficient; prosopamnesia would be associated with bilateral lesions. Individuals' face recognition would correspond to the specific elements (or items) of this "familiar faces" subsystem. De Renzi et al. (1991) introduced a similar distinction and separated two forms of prosopagnosia: aperceptive (as a disorder in face identification), and associative (as an amnesia for faces).

Most likely, we have learned to identify faces in the same way that an ornithologist has learned to identify birds or a farmer to identify individual animals. Some reports point to the possibility of a prosopagnosic deficit restricted to a very specific visual subcategory. Assal et al. (1984) reported a case of a peasant devoted to caring for cows with a restricted agnosia for cows, associated with a transient prosopagnosia for human faces, anterograde and retrograde amnesia, and topographic amnesia. The patient had difficulty in visual imagery for cows but not for other visual categories, and visual hypo-emotionality for cows' faces ("the cows have lost their personality and colorfulness"). This case of restricted zooagnosia supports the specificity in learned visual recognition of individuals within a particular visual subcategory. Difficulty in recognizing faces belonging to a different racial group are well known, whereas twins are easily recognized by their own parents and siblings.

Prosopagnosic patients usully recognize people when listening to their voices (e.g. Bodamer, 1947; Damasio et al., 1982). Disorders in voice recognition are associated with impairment of the ability to recognize individuals. Phonagnosia has been defined as the acquired inability to recognize and discriminate voices (Van Lancker and Carter, 1982). A further distinction has been introduced between the discrimination of familiar and unfamiliar voices (Van Lancker et al., 1988, 1989). Deficits in recognizing familiar voices are significantly correlated with damage to the inferior and lateral parietal regions of the right hemisphere, whereas impairment of voice discrimination abilities is associated with temporal damage to either hemisphere. This distinction clearly parallels the distinction between prosopagnosia and prosopamnesia (Lopera and Ardila, 1992). It is important to point out that voices (like faces) also convey emotional information. Occasionally, only auditory (but not visual) information is used to recognize a particular individual (e.g. through the telephone).

A whole array of neuropsychological syndromes could be associated with defects in the recognition of indiviuals: some types of visual agnosia (prosopagnosia, afilongnosia, asomagnosia), deficits in voices recognition (phonagnosia), and even disturbances in smell perception (hiposmia, anosmia and osmagnosia).

In summary, it can be proposed that people recognition is based, predominantly but not exclusively, on visual information. Different subsystems or modules can be distinguished. A first level analysis implies separating living (people, animals, plants) from non-living things (furniture, cars, etc.). Individual identification requires the distinction of familiar and non-familiar individuals. Additionally, gender and emotional states need to be 
recognized in order to achieve a unitary individual perception.

\section{CONCLUSIONS}

A great effort has been devoted in neurology and neuropsychology to the analysis of face recognition under normal, but mostly under pathological conditions. However, cultural differences in people recognition show that not only is facial perception relevant in individuals' identification, but also other visual signals, such as body and gait characteristics. Furthermore, not only visual information may be relevant for people recognition; auditory and even olfactory information may also be important in people identification. Visual information may be more important in daylight conditions, while auditory and olfactory signals may become relevant in dim conditions.

In cases of brain damage, sometimes one category or type of information can be preserved, while others are impaired. The following perceptual dissociations have been observed in brain-damaged patients: (1) perception of living and non-living things (Farah et al., 1991); (2) perception of own-species and other-species members; that is, people and animals (e.g. Benton, 1980, 1990; De Renzi, 1986b; Farah, 1990); (3) perception of familiar and nonfamiliar faces (e.g. Warrington and James, 1967; Bauer, 1984; De Haan and Young et al., 1987; De Haan et al., 1992; Lopera and Ardila, 1992); (4) face identification and recognition of emotional expressions (e.g. Shuttleworth $e t$ al., 1982; Bruyer et al., 1983; Feyereisen, 1986); (5) facial gender identification and whole-body gender identification (Ardila and Rosselli, unpublished); and (6) visual and auditory people recognition (e.g. Bodamer, 1947; Van Lancker et al., 1988, 1989).

Different subsystems (or "modules") could be involved in people recognition.

"People" could represent a subsystem included within the higher level "living things" system. One subgroup of this "people" subsystem includes "familiar individuals" (versus "non-familiar individuals"). "Familiar individuals" includes all the stock of known people, perhaps several thousands. The face can be enough to recognize an individual (although voice, gait, body configuration signals, etc., can also be enough to recognize the very same individual). Additionally, gender and emotional expression are conferred to familiar, but also to non-familiar persons. Gender and emotional expression can be recognized not only from visual, but also from auditory information. Individuals' recognition represents the final step in this people processing system. Individuals' recognition represents a complex perception, including multiple association systems (especially visual, but also auditory and even olfactory), and maintaining some specific emo- tional, memory, and even verbal (the individual's name) relationships.

\section{REFERENCES}

Assal G, Favre C and Anderes J (1984) Nonrecognition of familiar animals by a farmer: Zooagnosia or prosopagnosia for animals. Revue Neurologique, 140, 580-584.

Bauer RM (1982) Visual hipoemotionability as a sympton of visual-limbic disconnection in man. Archives of Neurology, 39, 702-708.

Bauer RM (1984) Autonomic recognition of names and faces in prosopagnosia: A neuropsychological application of the guilty test. Neuropsychologia, 22, 457-469.

Baylis GC, Rolls ET and Leonard CM (1985) Selectivity between faces in the responses of a population of neurons in the cortex in the superior temporal sulcus of the monkey. Brain Research, 342, 91-102.

Benson DF, Segarra J and Albert ML (1974) Visual agnosia-prosopagnosia. Archives of Neurology, 30, 307-310.

Benton A (1980) The neuropsychology of facial recognition. American Psychologist, 35, 176-186.

Benton A (1990) Facial recognition 1990. Cortex, 26, 491-499.

Benton AL and Van Allen MW (1972) Prosopagnosia and facial discrimination. Journal of Neurological Sciences, 15, 167-172.

Bodamer J (1947) Die prosopagnosie. Archiv fur Psychiatry und Nervenkrantheiten, 179, 6-53.

Bornstein B, Sroka H and Munitz H (1969) Prosopagnosia with animal face agnosia. Cortex, 5, 164-169.

Brugge JF and Reale RA (1985) Auditory cortex. In: Cerebral Cortex: Association and Auditory Cortices, Vol. 4 (Ed. A Peters and EG Jones), pp. 229-271. Plenum Press, New York.

Bruyer R (1986) The Neuropsychology of Face Perception and Face Expression. Lawrence Erlbaum, Hillsdale, NJ.

Bruyer R, Laterre C, Seron X, Feyereisne P, Strypstein E, Pierrard E and Rectem D (1983) A case of prosopagnosia with preserved covert remembrance of familiar faces. Brain and Condition, 2, 257-284.

Carlson NR (1986) Physiology of Behavior, 3rd edn. Allyn and Bacon, Boston.

Comfort A (1971) Likelihood of human pheromones. Nature, 230, 432-433.

Damasio AR (1985) Disorders of visual complex processing: Agnosia, achromatopsia, Balint's syndrome, and related difficulties in orientation and construction. In: Principles of Behavioral Neurology (Ed. MM Mesulam), pp. 259-288. F.A. Davis, Philadelphia.

Damasio AR, Damasio H and Van Hoesen GW (1982) Prosopagnosia: Anatomical basis and behavioral mechanisms. Neurology, 32, 331-341.

Damasio AR, Tranel D and Damasio H (1990) Face agnosia and the neural substrate of memory. Annual Review of Neuroscience, 13, 89-109.

De Haan EHF, Young WA and Newcombe F (1987) Face recognition without awareness. Cognitive Neuropsychology, 4, 385-415.

De Haan EHF, Bauer RN and Greve KW (1992) Behavioural and physiological evidence for covert face recognition in a prosopagnosic patient. Cortex, 28, 77-96.

De Renzi E (1986a) Prosopagnosia in two patients with CT scan evidence of damage confined to the right hemisphere. Neuropsychologia, 24, 385-389.

De Renzi E (1986b) Current issues in prosopagnosia. In: Aspects 
of Face Processing (Eds HD Ellis, MA Jeeves, F Newcombe and A Young), pp.243-252. Martinus Nijhoff, Dordrecht.

De Renzi E, Faglioni P, Grossi D and Nichelli P (1991) Apperceptive and associative forms of prosopagnosia. Cortex, 27, 213-221.

Desimone R, Albright TD, Gross CD and Bruce C (1984) Stimulus-selective responses of inferior temporal neurons in the macaque. Journal of Neuroscience, 4, 2051-2062.

Eibl-Eibesfeldt I. (1970) Ethology: The Biology of Behavior. Holt, Rinehart and Winston, New York.

Eibl-Eibesfeldt I (1973) Der Vorprogrammierte Mensch. Verlag Fritz Molden, Wien.

Etcoff NL (1984) Selective attention to facial identity and facial emotion. Neuropsychologia, 22, 281-295.

Ettlin TM, Beckson M, Benson DF, Langfitt JT, Amos EC and Pineda GS (1992) Prosopagnosia: a bihemispheric disorder. Cortex, 28, 129-134.

Fantz RL (1961) The origins of form perception. Scientific American, 204, 66-87.

Farah MJ (1990) Visual Agnosia. MIT Press, Cambridge, MA.

Farah MJ, Hammond KH, Mehta Z and Ratcliff G (1989) Category-specificity and modality-specificity in semantic memory. Neuropsychologia, 27, 193-200.

Farah MJ, McMullen PA and Meyer MM (1991) Can recognition of living things be selectively impaired? Neuropsychologia, 29, 185-193.

Feiberg TE, Gonzalez-Rothi L and Heilman KM (1986) Multimodal agnosia after unilateral left hemisphere damage. Neurology, 36, 864-867.

Feyereisen P (1986) Production and comprehension of emotional facial-expressions in brain-damaged subjects. In: Neuropsychology of Face Perception and Facial Expression (Ed. R Bruyer), pp. 221-245. Lawrence Erlbaum, Hillsdale, NJ.

Gross CG, Rocha-Miranda CG and Bender DB (1972) Visual properties of neurons in inferotemporal cortex of the macaque. Journal of Neurophysiology, 35, 96-111.

Hécaen H and Ajuriaguerra J (1956) Agnosie visualle pour les objects inanimes par lesion unilaterale gauche. Neurologique, 94, 222-233.

Heywood CA and Cowey A (1992) The role of the "face-cell" area in the discrimination and recognition of faces by monkeys. Philosophical Transactions of the Royal Society London, 335, 31-37.

Hinde RA (1970) Animal Behavior. McGraw-Hill Kogakusha, Tokyo.

Hinde RA (1974) The Biological Bases of Human Social Behaviour. McGraw-Hill, New York.

Jolly A (1972) The Evolution of Primate Behavior. Macmillan, New York.

Konorski J (1967) Integrative Activity of the Brain. Chicago University of Chicago Press, Chicago.

Kurucz C and Feldmar G (1979) Prosopo-affective agnosia as a symptom of cerebral organic disease. Journal of American Geriatric Society, 27, 225-230.

Landis T, Cummings JL, Christen L, Bogen JE and Imhof A (1986) Are unilateral right posterior cerebral lesions sufficient to cause prosopagnosia? Clinical and radiological findings in six additional patients. Cortex, 22, 242-252.

Landis T, Regard M, Blistle A and Kleihns P (1988) Prosopagnosia and non-canonical views: Autopsied case. Brain, 111, 1287-1297.
Lee RB and DeVore I (1968) Man the Hunter. Aldine, Chicago.

Lopera F and Ardila A (1992) Prosopamnesia and visuolimbic disconnection syndrome: a case study. Neuropsychology, 6 , 3-12.

Meadows JC (1974) The anatomical basis of prosopagnosia. Journal of Neurology, Neurosurgery and Psychiatry, 37, 489-501.

Modiano N, Maldonado LM and Villasana S (1982) Accurate perception of color illustrations: Rate of comprehension in Mexican indian children. Journal of Cross-Cultural Psychology, 13, 490-495.

Morris D (1977) Manwatching. A Field Guide to Human Behavior. Elsevier, New York.

Ojemann JG, Ojemann GA and Lettich E (1992) Neural activity related to faces and matching in human right nondominant temporal cortex. Brain, 115, 1-14.

Perret D, Rolls ET and Caan W (1982) Visual neurons responsive to faces in the monkey temporal cortex. Experimental Brain Research, 47, 329-342.

Perret D, Smith PA, Potteer DD, Mistlin AJ, Head AS, Milner AD and Jeeves MA (1984) Neurons responsive to faces in temporal cortex: studies of functional organization, sensitivity to identity and relation to perception. Human Neurobiology, $\mathbf{3}$, 197-208.

Rolls, ET (1984) Neurons in the cortex of temporal lobe and in the amygdala of the monkey with response selective for faces. Human Neurobiology, 3, 209-222.

Shutteworth E, Syring V and Allen N (1982) Further observations on the nature of prosopagnosia. Brain and Cognition, 1, 307-322.

Tinbergen N (1951) The Study of Instinct. Oxford University Press, London.

Tranel D and Damasio AR (1985) Knowledge without awareness: an autonomic index of facial recognition by prosopagnosics. Science, 228, 1453-1454.

Van den Berghe PL (1979) Human Family Systems. Elsevier, New York.

Van Lancker DR and Carter GJ (1982) Impairment of voice and face recognition in patients with hemispheric damage. Brain and Cognition, 1, 185-195.

Van Lancker DR, Cummings JL, Kreiman J and Dodkin BH (1988) Phonoagnosia: a dissociation between familiar and unfamiliar voices. Cortex, 24, 195-210.

Van Lancker DR, Kreiman L and Cummings JL (1989) Voice perception deficits: neuroanatomical correlates of phonoagnosia. Journal of Clinical and Experimental Neuropsycho$\log y, 11,665-674$.

Warrington EK and James M (1967) An experimental investigation of facial recognition in patients with unilateral cerebral lesion. Cortex, 3, 317-326.

Warrington EK and Shallice T (1984) Category specific semantic impairments. Brain, 107, 829-854.

Whiteley AM and Warrington EK (1977) Prosopagnosia: A clinical, psychological, and anatomical study of three patients. Journal of Neurology, Neurosurgery and Psychiatry, 40, 395-403.

Wilson AD (1975) Sociobiology. The Belknap Press of the Harvard University Press, Cambridge, MA.

Young AW and De Haan EHF (1988) Bounderies of covert recognition in prosopagnosia. Cognitive Neuropsychology, $\mathbf{5}$, 317-336. 


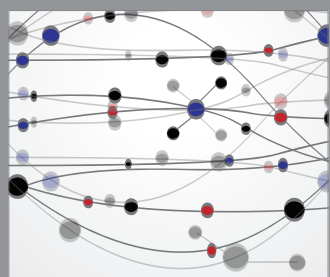

The Scientific World Journal
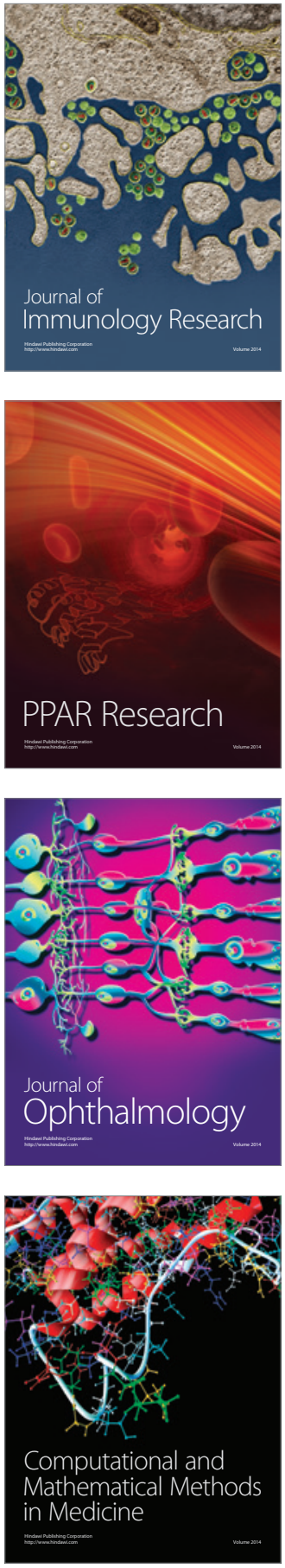

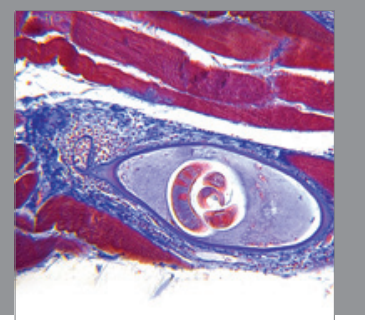

Gastroenterology

Research and Practice
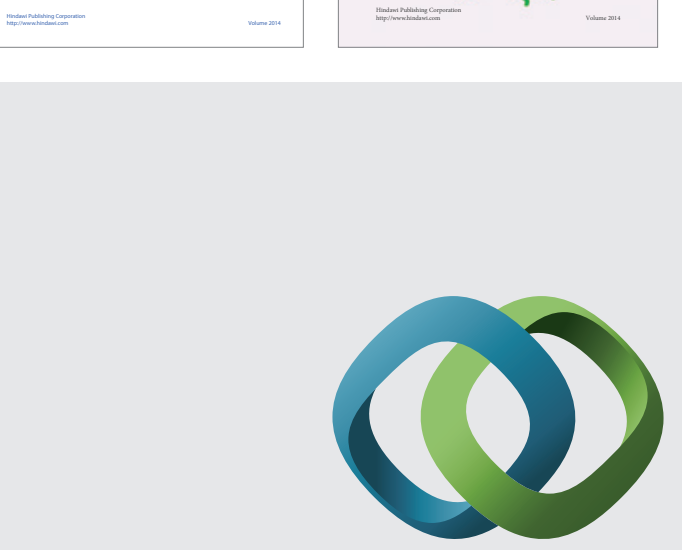

\section{Hindawi}

Submit your manuscripts at

http://www.hindawi.com
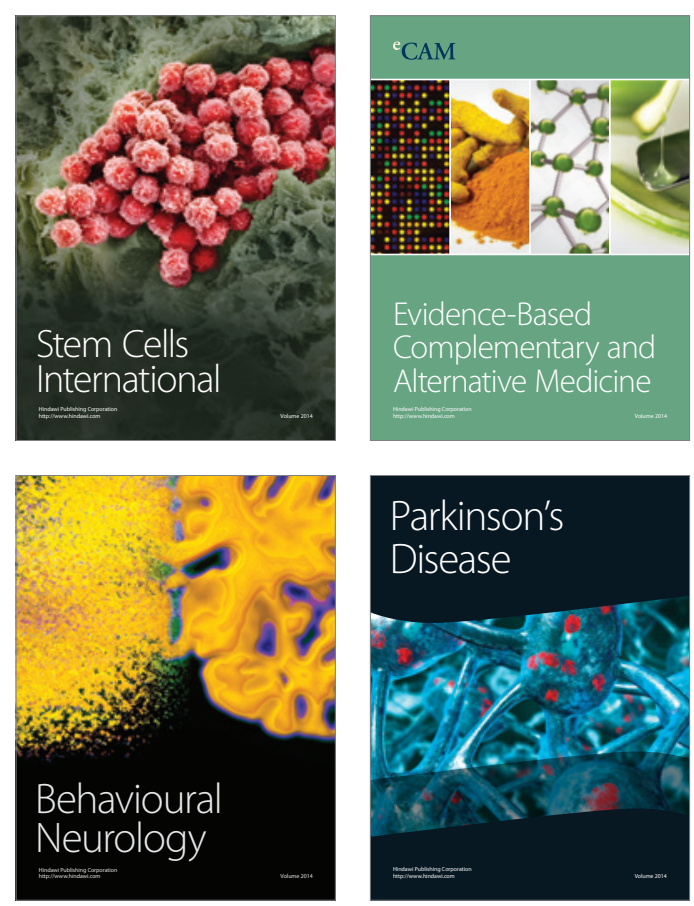

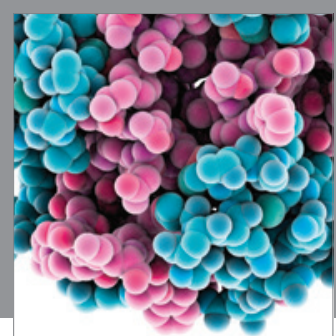

Journal of
Diabetes Research

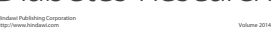

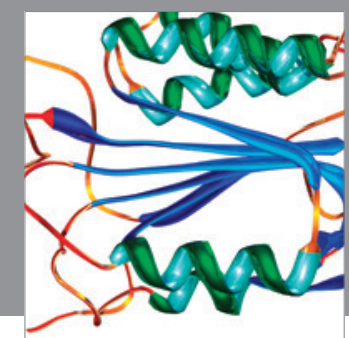

Disease Markers
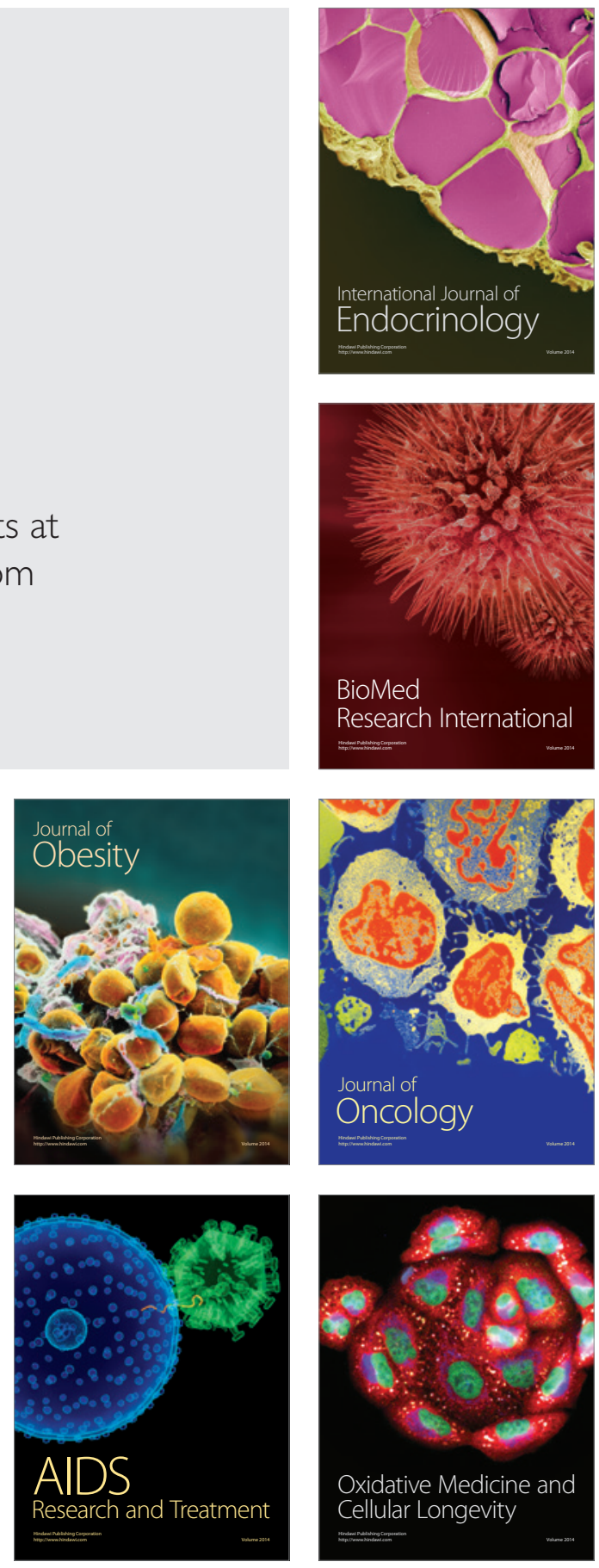